\title{
Comparison of the Effectiveness of the Transactional Analysis, Existential, Cognitive, and Integrated Group Therapies on Improving Problem-Solving Skills
}

\author{
Bahramali A. Ghanbari-e-Hashem-Abadi ${ }^{1}$, Mustafa Bolghan-Abadi ${ }^{2}$, \\ Zahra Vafaei-e-Jahan ${ }^{3}$, Raheleh Maddah-Shoorcheh ${ }^{3}$, \\ Elaheh Maddah-Shoorcheh ${ }^{4}$ \\ ${ }^{1}$ Ferdowsi University of Mashhad, Mashhad, Iran; \\ ${ }^{2}$ Family Counseling, Ferdowsi University of Mashhad, Mashhad, Iran; \\ ${ }^{3}$ General Psychology, Ferdowsi University of Mashhad, Mashhad, Iran; \\ ${ }^{4}$ Tabaran Institute Higher Education, Tabaran, Iran. \\ Email: mbolghan@gmail.com \\ Received January 15 $5^{\text {th }}, 2011$; revised March $18^{\text {th }}, 2011$; accepted April 25 $5^{\text {th }}, 2011$.
}

\begin{abstract}
Problem-solving is one of the necessities of life in twenty first century. Therefore, Psychologists consider it as a skill that everyone must learn it. The purpose of the present study is to compare the effectiveness of the transactional analysis, existential, cognitive, and integrated group therapies on improving problem-solving skills. For this purpose, 65 subjects of the clients who were referring to the Ferdowsi University of Mashhad's Mental Health Centre were selected randomly and subjects placed in 5 groups in random assignment method (13 participants in each group). The research method is Pre-test/Post-test control group design. To gather the data, Long \& Cassidy's problem solving styles questionnaire (1996) was used. In the descriptive level, the data were analyzed using mean and standard deviation, and in the inferential level Analysis of Covariance test (ANCOVA) was used. The results of data analysis were indicative of the fact that after modifying pretest scores, there was a significant difference between group's subjects. The results showed that group therapies were effective on improving problem-solving skills and that cognitive and integrated group therapies were more effective on improving problem-solving skills comparing to other groups. Regarding the results of the present study, it can be concluded that transactional analysis, existential, cognitive and integrated group therapies were effective on improving problem-solving skills of the clients who were referring to the Ferdowsi University of Mashhad's Mental Health Centre.
\end{abstract}

Keywords: Transactional Analysis Group Therapy, Existential Group Therapy, Cognitive Group Therapy, Integrated Group Therapy

\section{Introduction}

Problem-solving is a cognitive process by which the individual tries to find a suitable solution for the problem (Perla \& O’ Donnel, 2004). In problem-solving, finding a specific solution for a specific problem is not that much important, the thing that matters is to find an abstract rule or principle that can be generalized for other situations (Khoshkam, Malekpoor, \& Molavi, 2008). Problem-solving is a vital skill for life. Today in all activities, the authorities are called for thinking in a high level and problem-solving skills, whether in normal or complicated activities. And most of them emphasize that problem-solving skills must be improved (Poshtiban, 2007). When facing a Program, every individual uses a different method of problem-solving. Methods of problem-solving are: helplessness in solving a problem, problem-solving control, avoidance style, creative style, problem-solving confidence and approach style. The first there styles are called ineffective problem-solving methods and the last three styles are called effective problem-solving methods (Cassidy \& Long, 1996). Problem-solving is a coping skill which increases self-confidence and has a connection with good personal compatibility (Eizadi \&
Scpasi-Ashtiani, 2010). In problem-solving approach, therapy begins with focusing present goals. Focusing on present goals probably persuades the clients to concentrate on the problem and after that he/she will concentrate on the solutions.

Solutions are the results of conversations and each solution is unique (Prochaska \& Norcross, 2010). In the late 1960s and the early 1970 s, problem-solving started as a port of cognitive-behavioral movement to modify behavior. D'Zurilla \& Aoldfried who are the founders of this method in on article at American Psychological Association conference in 1968-emphasized on the necessity of teaching problem-solving skill in the program of teaching social skills. Since then, this method is used in a vast range of clinical counseling and psychotherapy situations and positive results are reported (Nezu \& D'zurrila, 2001).

Problem-solving is an intellectual process and is part of larger problem process that includes problem finding and problem shaping. Considered the most complex of all intellectual functions, problem-solving has been defined as higher-order cognitive process that requires the modulation and control of more routine or basic skills (Goldstein \& Levin, 1987). Problemsolving requires a variety of skills including clarifying informa- 
tion, programming and working methodically, checking outcomes and trying alternative strategies (Muir, Beswick, \& Williamson, 2008).

The issue of Problem-solving has attracted the attention of many researchers. The findings show that it is not so much important that people face problems and difficulties in their lives, but the thing which is important is to behave correctly when facing problems. Some people are not even able to solve their routine Problems and when facing a trivial problem they become embarrassed, upset and tense (Shokohi-Yekta \& Parands, 2008). According to the aforementioned materials, the necessity of teaching problem-solving skill becomes evident. The purpose of the present study is to find answers to this question: Is there any difference on improving problem-solving skill between the four therapy groups?

To achieve this goal, transactional analysis, existential, cognitive and integrated group therapies were formed which were based on teaching problem-solving skill. The hypothesis of the study suggests that after group therapies, there is difference between control group and experimental groups in the extent of problem-solving skill. Similar studies in problem-solving skill show that teaching problem-solving skill has been effective in decreasing Parent-child conflicts (Moradi \& Sanayi-e-zaker, 2006).

Shafea-Abad \& shams (2000) found that problem-solving skills instruction can significantly decrease the tendency to suicide, frustration and negative feelings of the youths who have attempted suicide. Heydori \& Rasolzadeh (2007) used teaching problem-solving skill decrease girl's escape from home and it was effective. Said et al., (2010) found that teaching problem-solving skill to families with children who have chronic asthma is effective on improving their life quality that is related to the children's health. A meta-analysis of the researches done in the field of problem-solving therapies was indicative of the fact that most of the problem-solving therapies had positive results on treating depression (Cuijpers, Straten, \& Warmerdam, 2007). In another meta-analysis on the effectiveness of problem-solving therapies in decreasing problems relating to physical and mental health showed that all the studies done in this area had a significant effect on decreasing psychical and mental health problems (Malouff, Thorsteinsson, \& Schutte, 2007).

The results of a study showed that cognitive group therapy which was based on problem-solving has positive effects on losing weight \& changing lifestyle of middle-aged American women (Murawsk et al., 2009). Cognitive functions and problem-solving skills have a significant difference between schizophrenia and healthy people (Zanello, Perring, \& Huguclet, 2006).

The purpose of the present study is to compare the effectiveness of the transactional analysis, existential, cognitive, and integrated group therapies on improving problem-solving skills. The hypotheses of the study are:

1) At the end of group therapies, there is a significant difference is posttest scores of control group and experimental groups.

2) At the end of group therapies, there is a significant difference in posttest scores of transactional analysis, existential, cognitive, and integrated experimental groups.

\section{Method}

The present study is a Pre-test/Post-test control group design. The population of the study was all clients who were referring to the Ferdowsi University of Mashhad's Mental Health Centre. From this population 65 subjects were selected randomly and were placed in 5 groups in random assignment method (13 participants in each group).

\section{Participants}

The participants' age of this study was between 18 to 30 years old. 33 subjects of them were master students $(50.77 \%)$ and 32 subjects of them $(49.23 \%)$ were bachelor students. 34 subjects of the participants were females $(52.31 \%)$ and 31 subjects were males $(47.69 \%)$. In cognitive group 8 females $(61.5 \%)$ and 5 males $(38.46 \%)$, in integrated group 3 females $(23.08 \%)$ and 10 males $(76.92 \%)$, in existential group 9 females $(69.23 \%)$ and 4 males $(30.77 \%)$, in transactional analysis group 7 females $(53.85 \%)$ and 6 males $(64.15 \%)$, and in control group 7 females (53.85\%) and 6 males (46.15\%) participated.

\section{Procedure}

Methods of interventions were transactional analysis, existential, cognitive and integrated group therapies with teaching problem-solving skills. Participants were randomly selected among students who had referred to the Ferdowsi University of Mashhad's Mental Health Centre. They were then randomly divided into five groups of 13 . Pretest measures were administered prior to the intervention. The experimental groups received eight 2-hourly intervention sessions which were weekly apart and last in 8 weeks. The same measures were administered at the posttest, which followed the last intervention session.

\section{Measure}

Problem-solving styles questionnaire: this questionnaire which was designed by Cassidy \& long (1996) containers 24 Items that have two choices which totally evaluates 6 factors or problem-solving styles. These factors are: 1) Helplessness style which shows that the individual is totally helplessness in problematic situation. 2) Control style that reflects inner-outer control in problematic situations. 3) Creative style which shows planning and considering various solutions. 4) Confidence style that believes the individual can solve the problem. 5) Avoidance style that reflects ignoring and rejecting the problem rather than facing it. 6) Approach style that shows positive attitude towards problems and tendency to face them.

Studies that result in designing and finding a norm are indicative of the fact that this measure is a useful, valid and reliable instrument to evaluate problem-solving methods (Mohammadi, 1997). Mohammadi and Sahebi (2001) reported the reliability of this instrument using Cronbach's alpha coefficient that equaled 0.66. In a study conducted by Babapoor Kheyrodin and Ezhey (2002) alpha coefficient was equal to 0.77. On the other hand, with considering the reliability index as validity coefficient (validity coefficient equals the second root of reliability coefficient) then validity coefficient is $87 \%$ (Babapoor kheyrodin \& Ezhey, 2002). 


\section{Results}

Table 1 shows means of posttests (which are modified after controlling the effect size of pretest) and standard deviation for problem-solving styles. Regarding research hypothesis and research method which was pretest-posttest experimental de- sign with control group, to analyze the data analysis of covariance test (ANCOVA) was used. Table 2 shows the results of analysis of covariance.

The results of analysis of covariance on the effect of 4 methods of group therapies that was accompanied with teaching problem-solving skills on improving problem-solving skills of

Table 1.

Estimated marginal means and Standard Deviation of Problem solving styles.

\begin{tabular}{|c|c|c|c|c|c|c|c|}
\hline group & & Approach & Avoidance & Confidence & Creativity & Control & Helplessness \\
\hline \multirow{2}{*}{ Cognitive } & $\mathrm{M}^{*}$ & 3.99 & 2.04 & 3.71 & 3.76 & 3.33 & 1.26 \\
\hline & $\mathrm{SD}^{* *}$ & .15 & .26 & .21 & .15 & .175 & .28 \\
\hline \multirow{2}{*}{ Integrative } & M & 3.91 & 1.56 & 3.12 & 3.52 & 2.74 & 1.97 \\
\hline & SD & .13 & .28 & .21 & .15 & .17 & .29 \\
\hline \multirow{2}{*}{ Existential } & M & 3.70 & 2.61 & 3.50 & 3.71 & 3.54 & .61 \\
\hline & SD & .13 & .26 & .21 & .15 & .17 & .28 \\
\hline \multirow{2}{*}{ Transactional } & M & 3.78 & 1.72 & 3.43 & 3.93 & 3.70 & .59 \\
\hline & $\mathrm{SD}$ & .13 & .27 & .21 & .15 & .17 & .28 \\
\hline \multirow{2}{*}{ Control } & M & 2.91 & 1.75 & 1.86 & 1.93 & 2.00 & .59 \\
\hline & SD & .13 & .27 & .21 & .15 & .17 & .28 \\
\hline
\end{tabular}

*Mean; **Standard Deviation.

Table 2.

Analysis of Covariance to control for the effect size of pre test.

\begin{tabular}{|c|c|c|c|c|c|c|c|c|}
\hline Variables & Source & $\mathrm{df}$ & Mean Square & $\mathrm{F}$ & $p$ & Partial Eta Squared & Observed Power & Adjusted $\mathrm{R}^{2}$ \\
\hline \multirow{3}{*}{ Approach } & Pretest & 1 & 4.23 & 20.41 & $<.000$ & .257 & .993 & \multirow{3}{*}{.46} \\
\hline & Group & 4 & 2.26 & \multirow{2}{*}{10.92} & \multirow{2}{*}{$<.000$} & \multirow{2}{*}{.425} & \multirow{2}{*}{1.000} & \\
\hline & Error & 59 & .21 & & & & & \\
\hline \multirow{3}{*}{ Avoidance } & Pretest & 1 & 16.78 & 18.76 & $<.000$ & .241 & .989 & \\
\hline & Group & 4 & 2.21 & \multirow{2}{*}{2.48} & \multirow{2}{*}{.054} & \multirow{2}{*}{.144} & \multirow{2}{*}{.671} & .30 \\
\hline & Error & 59 & .89 & & & & & \\
\hline \multirow{3}{*}{ Confidence } & Pretest & 1 & 6.78 & 11.93 & .001 & .168 & .925 & \\
\hline & Group & 4 & 5.76 & \multirow{2}{*}{10.13} & \multirow{2}{*}{$<.000$} & \multirow{2}{*}{.407} & \multirow{2}{*}{1.000} & .42 \\
\hline & Error & 59 & .57 & & & & & \\
\hline \multirow{3}{*}{ Creativity } & Pretest & 1 & 5.81 & 19.85 & $<.000$ & .252 & .992 & \\
\hline & Group & 4 & 8.62 & \multirow[b]{2}{*}{29.46} & \multirow[b]{2}{*}{$<.000$} & \multirow[b]{2}{*}{.666} & \multirow[b]{2}{*}{1.000} & .66 \\
\hline & Error & 59 & .29 & & & & & \\
\hline \multirow{3}{*}{ Control } & Pretest & 1 & 9.08 & 23.22 & $<.000$ & .282 & .997 & \\
\hline & Group & 4 & 6.32 & \multirow{2}{*}{16.15} & \multirow{2}{*}{$<.000$} & \multirow{2}{*}{.523} & \multirow{2}{*}{1.000} & .57 \\
\hline & Error & 59 & .39 & & & & & \\
\hline \multirow{3}{*}{ Helplessness } & Pretest & 1 & 10.91 & 11.03 & .002 & .158 & .904 & \\
\hline & Group & 4 & 4.34 & \multirow{2}{*}{4.40} & \multirow{2}{*}{.004} & \multirow[b]{2}{*}{.230} & \multirow{2}{*}{.916} & .21 \\
\hline & Error & 59 & .99 & & & & & \\
\hline
\end{tabular}


Table 3.

Pairwise comparisons by Bonferroni post hoc test.

\begin{tabular}{|c|c|c|c|c|c|c|c|}
\hline (I) group & (J) group & Helplessness & Control & Creative & Confidence & Avoidance & Approach \\
\hline & & $\mathrm{MD}^{* *}(\mathrm{I}-\mathrm{J})$ & MD (I-J) & $\mathrm{MD}(\mathrm{I}-\mathrm{J})$ & MD (I-J) & $\mathrm{MD}(\mathrm{I}-\mathrm{J})$ & MD (I-J) \\
\hline \multirow{4}{*}{ Cognitive } & Integrated & -.71 & .60 & .24 & .05 & .476 & .076 \\
\hline & Existential & .65 & -.20 & .052 & -.33 & -.570 & .286 \\
\hline & Transactional & .66 & -.37 & -.16 & -.26 & .318 & .190 \\
\hline & Control & .68 & $1.33^{*}$ & $1.84^{*}$ & $1.31^{*}$ & .285 & $1.07^{*}$ \\
\hline \multirow{3}{*}{ Integrated } & Existential & $1.36^{*}$ & $-.80^{*}$ & -.19 & -.38 & -1.046 & .211 \\
\hline & Transactional & $1.37^{*}$ & $-.96^{*}$ & -.41 & -.31 & -.157 & .114 \\
\hline & Control & $1.39^{*}$ & $.73^{*}$ & $1.59^{*}$ & $1.26^{*}$ & -.191 & $1.00^{*}$ \\
\hline \multirow{2}{*}{ Existential } & Existential & .015 & -.16 & -.21 & -.07 & -.888 & -.10 \\
\hline & Transactional & .029 & $1.54^{*}$ & $1.78^{*}$ & $1.57^{*}$ & -.033 & $.79^{*}$ \\
\hline
\end{tabular}

*The mean difference is significant at the .05 level; **Mean difference.

clients who were referring to the Ferdowsi University of Mash had's Mental Health Centre written in Table 2 shows that after modifying the scores of problem-solving skills using analysis of covariance test, there was a significant difference between the scores of experimental groups and control group in approach style $\left(\mathrm{F}_{(4,59)}=20.41, \mathrm{P}=<.000\right)$ Confidence style $\left(\mathrm{F}_{(4,59)}\right.$ $=10.13, \mathrm{P}=<.000)$, Creativity style $\left(\mathrm{F}_{(4,59)}=29.46, \mathrm{p}=<.000\right)$, Control style $\left(\mathrm{F}_{(4,59)}=16.15, \mathrm{P}=<.000\right)$ and Helplessness style $\left(\mathrm{F}_{(4,59)}=4.40, \mathrm{P}=.230\right)$ except avoidance style $\left(\mathrm{F}_{(4,59)}=2.48, \mathrm{P}\right.$ $=.054)$.

According to Table 2, the main effect of group therapy is significant in all problem-solving styles except avoidance style. Therefore, to compare pairwise of groups Bonferroni post hoc test was used. According to Table 3 the results of Bonferroni post hoc test showed that in confidence, approach, and creative styles there was no significant difference between intervention groups. In control style existential intervention group (I) was more effective comparing integrated intervention group $(\mathrm{J})(p=$ $\left.0.018, \mathrm{MD}^{1}=0.80\right)$, and also transactional analysis intervention group was more effective comparing integrated intervention group $(p=0.002, \mathrm{MD}=0.96)$. In helplessness style integrated intervention group (I) was more effective comparing existential $(\mathrm{J})$ and transactional $(\mathrm{J})$ intervention groups. In avoidance style, none of the intervention groups were effective on its improving.

\section{Conclusion}

The aim of the study is the comparing the effectiveness of the transactional analysis, existential, cognitive, and integrated group therapies on improving problem-solving skills. The results of the study show that transactional analysis, existential, cognitive, and integrated intervention groups are effective on improving problem-solving skills. It is to be noted that transactional analysis and existential group therapies had better function comparing to integrated group therapy.

\section{Discussion}

Problem-solving intervention therapy has been effective in

${ }^{1}$ Mean difference. reducing depression symptoms (Bell \& D'Zurilla, 2009), changing and improving child-rearing style (Shure \& Spivack, 1978), reducing self-efficiency and improving students' scores (Dekovis \& Buist, 2005), reducing family's emotional contribution (Shokohi-Yekta \& Parand, 2008), reducing exam's anxiety and improving students' educational issues (Eizadi \& Sepasi-Ashtiona, 2010), reducing symptoms of Attentionseficit/hyperactivity disorder (Neshatdoost, Kalantari, \& Solati, 2001). Since group therapies were based on problem-solving and the results of group therapies were effective on improving problem-solving styles, therefore, it can be concluded that these group interventions or group therapies can improve student's problem-solving styles and it is hoped to result in improving other psychic aspects. According to the previous studies the problem-solving is an important skill in life, then individuals have this skill can cope with your depression (Bell \& D'Zurilla, 2009), can improve your parenting style (Shure \& Spivack, 1978), have self-efficacy in your life (Dekovis \& Buist, 2005), and so on.

\section{References}

Bell, A. C., \& D'Zurilla, T. J. (2009). Problem-solving therapy for depression: A meta-analysis. Clinical Psychology Review, 29, 348-353. doi:10.1016/j.cpr.2009.02.003

Babapoor, K. J., \& Ezheyi, M. J. (2002). The study of relationship between problem-solving styles, conflict solving styles, and mental health among Tarbiat Modarres University students. Journal of Psychology, 7, 3-16.

Cassidy, T., \& Long, C. (1996). Problem-solving style, stress and psychology illness: Development of multifactorial measure. British Journal of Clinical Psychology, 35, 265-277. doi:10.1111/j.2044-8260.1996.tb01181.x

Cuijpers, P., Straten von, A., \& Warmerdam, L. (2007). Problem solving therapies for depression: A meta-analysis. European Psychiatry, 22, 9-15. doi:10.1016/j.eurpsy.2006.11.001

Dekovic, M., \& Buist, K. L. (2005). Multiple perspectives within the family. Journal of Family Issues, 29, 467-490. doi: $10.1177 / 0192513 X 04272617$

Eizadi, F. R., \& Sepasi, A. M. (2010). Effectiveness of cognitive-behavioral therapy with problem solving skills training on reduction of test anxiety symptoms. Journal of Behavioral Sciences, 4, 23-27. 
Goldstein, F. C., \& Levin, H. S. (1987). Disorders of reasoning and problem-solving ability. In M. Meier, A. Benton and L. Diller (Eds.), Neuropsychological rehabilitation. London: Taylor \& Francis Group.

Heydari, Sh., \& Rasolzadeh, T. K. (2007). Study of effectiveness of problem solving instruction on reducing of tendency of escape in adolescent girls. The Quarterly of Family Research, 3, 573-585.

Khoshkam, Z., Malekpoor, M., \& Molavi, H. (2008). The effectiveness of instruction of group problem solving on students' social skills with visual injury. Research on Exceptional Children, 8, 141-156.

Malouff, J. M., Thorsteinsson, E. B., \& Schutte, N. S. (2007). The efficacy of problem solving therapy in reducing mental and physical health problems: A meta-analysis. Clinical Psychology Review, 27, 46-57. doi:10.1016/j.cpr.2005.12.005

Mohammadi, F. (1997). Comparison of problem solving styles among depressed and normal individuals. Postgraduate Dissertation, Mashhad: Ferdowsi University of Mashhad, unpublished.

Mohammadi, F., \& Sahebi, A. (2001). The study of comparison of problem-solving among depression and normal human. Journal of psychological Sciences, 1, 24-42.

Moradi, O., \& Sanayi-e-Zaker, B. (2006). Study of effectiveness of problem solving skills on parent-child conflicts in high school students in Tehran. New Things and Researches of Counseling, 5, 23-38.

Muir, T., Beswick, K., \& Williamson, J. (2008). "I'm not very good at solving problems": An exploration of students' problem solving behaviours. The Journal of Mathematical Behavior, 27, 228-241. doi:10.1016/j.jmathb.2008.04.003

Murawski, M. E., Milsom, V. A., Ross, M. K., Rickel, K. A., DeBraganza, N., Gibbons, L. M., \& Perri, M. G. (2009). Problem solving, treatment adherence, and weight-loss outcome among women participating in lifestyle treatment for obesity. Eating Behaviors, 10, 146-151. doi:10.1016/j.eatbeh.2009.03.005

Neshatdoost, H., Kalantari, M., \& Soltani, A. (2001). The study of effectiveness of problem solving instruction on reducing of attention deficit hyperactivity disorders symptoms. The Journal of New Things of Cognitive Sciences, 3, 46-52.

Nezu, A., \& D'Zurrilla, T. J. (2001). Problem solving training, handbook of cognitive behavior therapies. New York: Guilford.

Perla, E., and O' Donnel, B. (2004). Encouraging problem solving in orientation and mobility. Journal of Visual Impairment \& Blindness, 98, 47-52.

Poshtiban, A. (2007). The relationship between problem solving styles with academic achievement, self esteem, and thought manner in seniors of Tabriz. Postgraduate Dissertation, Tabriz: Tabriz University, unpublished.

Prochaska, J. O., \& Norcross, J. C. (2010). Systems of psychotherapy: A transtheoretical analysis (7th Ed.). Pacific Grove, CA: Brooks/ Cole.

Seid, M., Varni, J. W., Gidwani, P., Gelhard, L. R., \& Slymen, D. J. (2010). Problem-solving skills training for vulnerable families of children with persistent asthma: Report of a randomized trial on health-related quality of life outcomes. Journal of Pediatric Psychology, 35, 33-43. doi:10.1093/jpepsy/jsp133

Shafea, A. A., \& Shams, S. (2000). The study of effectiveness of problem solving skills instruction on cognitive features in adolescents who have attempted suicide. Research and New Issues in Counseling, 2, 21-40.

Shokohi, Y. M., \& Parand, A. (2008). The effectiveness of instruction based on cognitive approach on family relationship. Journal of Family Research, 4, 5-16.

Shure, M. B., \& Spivack, G. (1978). Problem solving techniques in childrearing. San Francisco, CA: Jossey-Bass.

Zanello, A., Perrig, L., \& Huguelet, P. (2006). Cognitive functions related to interpersonal problem-solving skills in schizophrenic patients compared with healthy subjects. Psychiatry Research, 142, 67-78. doi:10.1016/j.psychres.2003.07.009 